\title{
PENERAPAN MODEL PEMBELAJARAN VAK (VISUALIZATION, AUDITORY, DAN KINESTETHIC) TERHADAP HASIL BELAJAR IPA PESERTA DIDIK KELAS IV SD NEGERI 147 PEKANBARU
}

\author{
Triyan Desti Elisa, Neni Hermita, Eddy Noviana \\ Pendidikan Guru Sekolah Dasar FKIP Universitas Riau \\ Email: triyandelisa@gmail.com, Neni.hermita1@lecturer.ac.id, \\ eddy.noviana@lecturer.unri.ac.id
}

\begin{abstract}
This research is motivated by the low involvement of students in learning. This study aims to determine the differences in the learning outcomes of science students between the experimental class and the control class by applying the learning model VAK. This study uses quasi-experimental methods with a nonequivalent control group design. This research was conducted in 147 Public Elementary Schools Pekanbaru with class IV D as the experimental class and class IV A as the control class. Based on the results of the study, it can be seen from the experimental class pretest score of 51.25 and posttest which is 80.63. In the control class the average score of the pretest was 45.53 and posttest was 72.89.The score of the average gain of experimental class science learning outcomes is 0.62 and the average score of the control class is 0.50 . The results of the t-test gain score average $t_{\text {hitung }}>t_{\text {tabel }}$ or 2,89966 > 1,99547 then Ha is accepted. Based on the results of the t gain test between the experimental class and the control class there were differences in learning outcomes IPA student learning in class IVSD Negeri 147 Pekanbaru which are significant.
\end{abstract}

Keywords:VAK Learning Model, Science Learning Outcomes

Abstrak.Penelitian ini dilatarbelakangi oleh rendahnya keterlibatan peserta didik dalam pembelajaran. Penelitian ini bertujuan untuk mengetahui perbedaan hasil belajar IPA peserta didik antara kelas eksperimen dan kelas kontrol dengan penerapan model pembelajaran VAK. Penelitian ini menggunakan metode eksperimen semu (quasi eksperiment) dengan desain nonequivalent control group design. Penelitian ini dilakukan di SD Negeri 147 Pekanbaru dengan kelas IV D sebagai kelas eksperimen dan kelas IV A sebagai kelas kontrol. Berdasarkan hasil penelitian terlihat dari skor pretest kelas eksperimen yaitu 51,25 dan posttest yaitu 80,63. Pada kelas kontrol skor rata-rata pretest yaitu 45,53 dan posttest yaitu 72,89. Hasi skor rata-rata gain hasil belajar IPA kelas eksperimen yaitu 0,62 dan skor rata-rata kelas kontrol yaitu 0,50. Hasil uji $t$ gain skor rata-rata $t_{\text {hitung }}>t_{\text {tabel }}$ atau 2,89966 > 1,99547, maka $\mathrm{H}_{\mathrm{a}}$ diterima. Berdasarkan hasil Uji t gain antara kelas eksperimen dan kelas kontrol ada perbedaan hasil belajar IPA peserta didik kelas IV SD Negeri 147 Pekanbaru yang signifikan.

Kata kunci: Model Pembelajaran VAK, Hasil Belajar IPA 


\section{Triyan Desti Elisa, Neni Hermita, Eddy Noviana}

\section{PENDAHULUAN}

Pembelajaran yang diterapkan
pada kurikulum 2013 adalah
pembelajaran tematik dan pendekatan
yang digunakan yaitu pendekatan Scientific. Tujuan pendekatan tersebut yaitu cara untuk mengatasi kebosenan dan untuk meningkatkan kemampuan belajar peserta didik, karena dalam pendekatan Scientific ada lima proses yang dilaksanakan dalam pembelajaran yaitu: mengamati, menanya, mencoba, mengasosiasi, dan kemudian mengkomunikasikan. Proses pembelajaran berbasis tematik didasarkan pada tema kemudian dikaitkan dengan mata pelajaran: Bahasa Indonesia, PPKn, IPA, IPS, dan SBdP.

Pembelajaran IPA disekolah merupakan pembelajaran yang menyenangkan dan tidak membosankan tidak terlepas dari kegiatan mengamati, menyimak atau mendengar dan aktivitas fisik karena seseorang membangun suatu pengetahuan melalui fakta atau kejadian yang dapat diketahui dengan memanfaatkan fungsi panca indera terutama penglihatan, pendengaran, serta membuktikan melalui aktivitas fisik.

Namun pada kenyataannya bahwa kualitas pembelajaran IPA di sekolah masih sangat rendah. Karena terdapat permasalahan pada kegiatan dalam pembelajaran IPA salah satunya di kelas di kelas IVD terutama dalam meningkatkan kemampuan belajar peserta didik di kelas. Suasana di dalam kelas terkesan kaku dan peserta didik banyak yang diam dan tidak memperhatikan guru menerangkan materi pembelajaran.

Permasalahan

tersebut

dikarenakan peserta didik yang kurang dilibatkan untuk menemukan dan mengembangkan pengetahuan yang dimilikinya serta banyaknya guru yang masih menggunakan model pembelajaran konvensional. Hal tersebut berdampak pada kurangnyapenguasaan peserta didik terhadap materi yang diberikan.

Menyadari

pentingnya

pembelajaran IPA bagi peserta didik maka dibutuhkan keterlibatan siswa dan guru secara optimal agar tercapainya proses belajar yang baik. Salah satu tolok ukur bahwa siswa telah belajar dengan baik adalah jika peserta didik itu dapat mempelajari apa yang seharusnya dipelajari, sehingga indikator hasil belajar yang diinginkan dapat dicapai oleh siswa (Trianto 2015). Hasil belajar yang baik merupakan buah dari proses belajar mengajar yang baik pula karena hasil belajar berbanding lurus dengan proses belajar mengajar.

Salah satunya yaitu dengan menerapkan model pembelajaran yang menarik dan inovatif yang dapat membangkitkan semangat belajar yaitu dengan menggunkan model pembelajaran VAK. Model pembelajaran VAK adalah model pembelajaran yang mengkombinasikan ketiga gaya belajar (melihat, mendengar dan bergerak) setiap individu dengan cara memanfaatkan potensi yang telah dimiliki dengan melatih dan mengembangkannya, agar semua kebiasaan belajar siswa terpenuhi (Sugiyanto dalam Suryadin, dkk, 2017).

Pada model pembelajaran VAK, pembelajaran difokuskan pada pemberian pengalaman belajar secara langsung dan menyenangkan. Pengalaman belajar secara langsung dengan cara belajar mengingat (visual), belajar dengan mendengar (auditori), dan belajar dengan gerak dan emosi (kinestetik) (Deporter, dkk, dalam Ari, S, 2014). Pembelajaran akan berlangsung efektif dan efisien dengan memperhatikan ketiga gaya belajar tersebut. Setiap peserta didik akan terpenuhi kebutuhannya sehingga mereka termotivasi dalam kegiatan pembelajaran.

Berdasarkan permasalahan di atas, peneliti tertarik untuk meneliti dan 
mengetahui hasil belajar IPA peserta didik dalam suatu penelitian yang berjudul "Penerapan Model

eksperiment)dengan desain Pembelajaran VAK (Visualization, nonequivalent control group design.

$$
\mathrm{g}=\frac{\text { skor posttest }- \text { skor pretest }}{\text { skor ideal }- \text { skor pretest }}
$$

Tabel 1

Kategori perubahan skor N-gain

\begin{tabular}{cc}
\hline Batasan & Kategori \\
\hline $\mathrm{g}>0,7$ & Tinggi \\
$0,3<\mathrm{g} \leq 0,7$ & Sedang \\
$\mathrm{g} \leq 0,3$ & Rendah \\
\hline
\end{tabular}

Sumber: Meltzer dalam Hermita, N (2008)

Auditory, dan Kinestethic) terhadap Hasil Belajar IPA Peserta Didik Kelas IV SD Negeri 147 Pekanbaru".

Tujuan penelitian ini adalah untuk mengetahui perbedaan hasil belajar IPA peserta didik kelas IV SD Negeri 147 Pekanbaru antara kelas eksperimen dan kelas kontrol dengan penerapan model pembelajaran VAK (Visualization, Auditory, dan Kinestethic).

\section{METODE PENELITIAN}

Subjek pada penelitian ini adalah peserta didik di SD Negeri 147 Pekanbaru, kegiatan penelitian ini dilakukan semester ganjil pada bulan November Tahun ajaran 2018/2019. Dalam penelitian ini dipilih dan ditentukan bahwa kelas IVA yang berjumlah 32 orang peserta didik dan kelas IVD berjumlah 38 orang peserta didik. Untuk menetapkan kelas eksperimen dan kelas kontrol antara kelas IVA dan kelas IVD dalam penelitian ini yaitu pengambilan atas dasar tujuan (purposive sampling) dimana sampel dipilih atas pertimbangan-pertimbangan tertentu dengan tujuan tertentu.

Penelitian ini menggunakan metode eksperimen semu (quasi pretest-posttest control group design, hanya pada desain ini kelompok eksperimen maupun kelompok kontrol tidak dipilih secara random (Sugiyono, 2012).

Data yang dikumpulkan dalam penelitian ini berupa tes hasil belajar dan lembar aktivitas guru dan peserta didik. Data dalam penelitian ini adalah data kuantitatif berupa data hasil belajar peserta didik. Tes digunakan pada penelitian ini berupa tes objektif dengan bentuk pilihan ganda. Pada kelas eksperimen diberi perlakuan yaitu dengan menerapkan model pembelajaran VAKdan pada kelas kontrol diberi perlakuan pembelajaran biasa. Setelah itu kedua kelas diberi posttest untuk mengukur pemahaman peserta didik mengenaimateri yang diajarkan dan mengetahui hasil belajar IPA peserta didik setelah diberi perlakuan.

Sebelum dianalisis terlebih dahulu dilakukan pemberian skor terhadap hasil belajar tes berupa pretest dan posttest. Untuk memberikan gambaran umum peningkatan hasil belajar antara sebelum dan sesudah pembelajaran. Gain adalah selisih antara nilai pretest dan posttest.

Besarnya peningkatan sebelum dan sesudah pembelajaran dihitung dengan rumus gain ternormalisasi 
Triyan Desti Elisa, Neni Hermita, Eddy Noviana

(normalized gain) yang dikembangkan

Hake dalam Sundayana, R (2014). hipotesis. Tujuan uji hipotesis adalah untuk membandingkan (membedakan) apakah kedua variabel tersebut sama atau

Jika sebaran data normal dan berbeda dengan rumus: homogen, dilakukan uji $\mathrm{t}$ atau uji

$$
\left.\mathrm{t}_{\text {hitung }}=\frac{\overline{\mathrm{x}}_{1}+\overline{\mathrm{x}}_{2}}{s_{\text {gabungan }} \sqrt{\frac{n_{1}+n_{2}}{n_{1} \cdot n_{2}}}} \text {, dengan } \mathrm{dk}=\mathrm{n}_{1}+\mathrm{n}_{2}-2, \ldots \ldots \text { (Sundayana, } \mathrm{R}, 2014\right)
$$

Dengan:

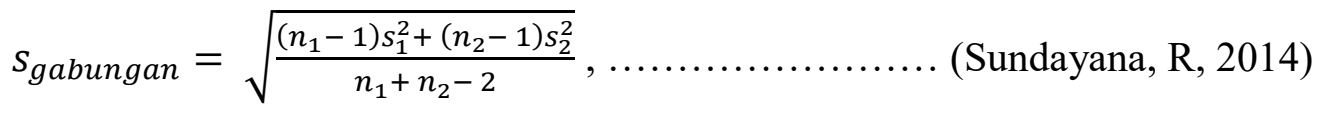

(Sundayana, R, 2014)

Dengan kriteria:

$-t_{\text {tabel }} \leq \mathrm{t}_{\text {hitung }} \leq \mathrm{t}_{\text {tabel }}$ maka $\mathrm{H}_{\mathrm{o}}$ diterima

\section{HASILPENELITIAN}

\section{Hasil Belajar}

Berdasarkan hasil pengolahan pretest, skor posttest peserta didik dalam pembelajaran IPA di SD Negeri 147 Pekanbaru tahun 2018/2019 dan gain yang dinormalisasi data hasil belajar. Besarnya peningkatan hasil belajar IPA sebelum dan sesudah pembelajaran dihitung dengan rumus gain ternormalisasi (normalized gain). Adapun hasil uji gain dalam penelitian ini dapat dilihat pada tabel berikut

Tabel 2

Analisis peningkatan skor pretest dan posttest kelas eksperimen dan kelas kontrol

\begin{tabular}{ccccccc}
\hline & Kelas & Kode PS & Pretest & Posttest & Gain & Interprestasi \\
\hline \multirow{2}{*}{ Subtema } & \multirow{2}{*}{\begin{tabular}{c}
\multirow{2}{*}{ Eksperimen } \\
\end{tabular}} & Jumlah & 1900 & 2505,88 & 16,98 & \multirow{2}{*}{ Sedang } \\
& \multirow{2}{*}{ Kontrol } & Jumlah & 59,38 & 81,43 & 0,53 & \\
& & $\bar{x}$ & 53,41 & 72,60 & 0,37 & \multirow{2}{*}{ Sedang } \\
\hline \multirow{2}{*}{ IPA } & \multirow{2}{*}{ Eksperimen } & Jumlah & 1640 & 2580 & 20,00 & \multirow{2}{*}{ Sedang } \\
& \multirow{2}{*}{ Kontrol } & $\bar{x}$ & 51,25 & 80,63 & 0,62 & \\
& & Jumlah & 1730 & 2770 & 19,09 & \multirow{2}{*}{ Sedang } \\
& & $\bar{x}$ & 45,53 & 72,89 & 0,50 & \\
& & &
\end{tabular}

Berdasarkan tabel 2 bahwa terjadi peningkatan antara skor pretest dan skor posttest hasil belajar IPA pada kelas eksperimen dan kelas kontrol. Pada kelas eksperimen skor pretest terdapat jumlah skor yaitu 1640 dengan rata-rata 51,25. Skor tersebut mengalami kenaikan. Terlihat pada jumlah skor posttest yaitu 2580 dengan rata-rata 80,63. Pada kelas kontrol skor pretest jumlah skor yaitu 1730 dengan rata-rata 45,53. Terlihat pada jumlah skor posttest yaitu 2770 dengan rata-rata 72,89. Adapun $\mathrm{N}-$ Gain hasil belajar IPA pada kelas eksperimen berjumlah 20,00 dengan rata-rata indeks gain yaitu 0,62 dan masuk kedalam kategori sedang. Sedangkan pada kelas kontrol N-Gain hasil belajar IPA berjumlah 19,09 dengan rata-rata 0,50 dan masuk dalam kategori sedang.

Pada kelas eksperimen bahwa $\mathrm{L}_{\text {makx }}$ $<\mathrm{L}_{\text {tabel }}$ yaitu $\mathrm{L}_{\text {makx }}=0,124$ sedangkan $\mathrm{L}_{\text {tabel }}=0,159$ dengan jumlah peserta didik 32 orang. Sedangkan pada kelas kontrol $\mathrm{L}_{\text {makx }}<\mathrm{L}_{\text {tabel }}$ yaitu $\mathrm{L}_{\text {makx }}=0,079$ sedangkan $\mathrm{L}_{\text {tabel }}=0,145$ dengan jumlah peserta didik 38 orang. Dari data tersebut 
dapat diputuskan bahwa kelas eksperimen dan kelas kontrol N-Gain berdistribusi Normal. Hasil perhitungan homogenitas skor pretest dan posttest menunjukkan bahwa hasil belajar IPA peserta didik dari kelas eksperimen dan kelas kontrol memenuhi kriteria $\mathrm{F}_{\text {hitung }}<$ $\mathrm{F}_{\text {tabel }} \mathrm{H}_{\mathrm{o}}$ diterima (varian homogen)ini berarti bahwa varians kelas eksperimen dan kelas kontrol pada pretest dan posttest bervarians homogen. Setelah memenuhi kriteria maka dapat dilakukan uji $\mathrm{t}$ atau uji hipotesis. Uji $\mathrm{t}$ untuk mengetahui ada atau tidaknya perbedaan yang signifikan antara hasil belajar IPA kelas eksperimen dan kelas kontrol dengan hipotesis sebagai beriku

$\mathrm{Ha}$ : Ada perbedaan hasil belajar IPA yang signifikan antara kelas eksperimen dan kelas kontrol dengan menggunakan model pembelajaran VAK.

$\mathrm{H}_{\mathrm{o}}$ : Tidak ada perbedaan hasil belajar IPA yang signifikan antara kelas eksperimen dan kelas kontrol dengan menggunakan model pembelajaran VAK.

Adapun hasil uji t hasil belajar IPA skor pretest dan posttest pada kelas eksperimen dan kelas kontrol dapat disimpulkan bahwa pada pretest tidak terdapat perbedaan hasil belajar IPA yang signifikan antara kelas eksperimen dan kelas kontrol yang artinya $\mathrm{H}_{\mathrm{o}}$ diterima dan $\mathrm{H}_{\mathrm{a}}$ ditolak. Selanjutnya pada posttest dapat dilihat bahwa nilai $t_{\text {hitung }}>t_{\text {tabel, }}$ maka terdapat perbedaan hasil belajar IPA yang signifikan antara kelas eksperimen dan kelas kontrol dengan menggunakan model pembelajaran VAK yang artinya $\mathrm{H}_{\mathrm{o}}$ ditolak dan $\mathrm{H}_{\mathrm{a}}$ diterima. Pada uji t Gain dapat dilihat bahwa nilai $\mathrm{t}_{\text {hitung }}>\mathrm{t}_{\text {tabel }}$ atau 2,89966 > 1,99547 yang artinya $\mathrm{H}_{\mathrm{o}}$ ditolak dan $\mathrm{H}_{\mathrm{a}}$ diterima. Hal ini membuktikan bahwa hasil belajar IPA peserta didik pada skor pretest dengan skor posttest di kelas eksperimen dan kelas kontrol ada perbedaan hasil belajar IPA yang signifikan.

\section{DISKUSI}

Hasil belajar IPA peserta didik kelas IV SD Negeri 147 Pekanbaru merupakan hasil perlakuan yang diberikan kepada peserta didik dengan menggunakan model pembelajaran VAK. Perlakuan dalam penelitian ini pada tema 5 subtema 1 pembelajaran 1 sampai pembelajaran 6. Untuk pembelajaran IPA dilakukan sebanyak 2 kali pertemuan yaitu pada pembelajaran 1 dan pembelajaran 3. Pada kelas eksperimen setiap pertemuan sudah dirancang sesuai dengan langkahlangkah model pembelajaran VAK. Sedangkan pada kelas kontrol yaitu menerapkan pembelajaran konvensional.

Peningkatan hasil belajar IPA peserta didik kelas IV SD Negeri 147 Pekanbaru setelah melakukan penelitian ini karena melibatkan peserta didik dalam proses pembelajaran dan menjadikan peserta didik mampu untuk berinteraksi dengan baik sehingga peserta didik ikut aktif di kelas. Pembelajaran dengan menggunakan model ini menjadikan peserta didik agar dapat mengkombinasikan 2ketiga modalitas gaya belajar tersebut pembelajaran di kelas menjadi lebih menarik dan tidak membosankan, peserta didik juga bisa memanfaatkan modalitas serta potensi yang dimilikinya dengan belajar mengalami secara langsung (Herdian dalam Shoimin, A, 2014)

Mata pelajaran IPA memerlukan kemampuan guru dalam mengelola pembelajaran sehinggan keterlibatan 


\section{Triyan Desti Elisa, Neni Hermita, Eddy Noviana}

peserta didik dapat maksimal, yang pada akhirnya akan berdampak pada hasil belajar yang optimal. Pembelajaran IPA tidak terlepas dari kegiatan mengamati, menyimak atau mendengar dan aktivitas fisik karena seseorang membangun suatu pengetahuan melalui fakta atau kejadian yang dapat diketahui dengan memanfaatkan fungsi panca indera terutama penglihatan, pendengaran, serta membuktikan melalui aktivitas fisik (Trianto, 2015).

Hasil dari penelitian ini telah membuktikan bahwa terdapat perbedaan hasil belajar IPA peserta didik kelas IV SD Negeri 147 Pekanbaru yang signifikan antara kelas eksperimen dan kelas kontrol dengan penerapan model pembelajaran VAK. Kartika Hartanti (2014) mengatakan bahwa model pembelajaran VAK ini difokuskan pada pembelajaran langsung dan menyenangkan. Pengalaman belajar secara langsung dengan cara belajar dengan mengingat (visual), belajar dengan cara mendengar (auditory), dan belajar dengan melakukan aktifitas fisik atau emosi dan gerak (kinestethic). Model pembelajaran ini merupakan model pembelajaran yang efektif dan menumbuhkan rasa minat siswa. Dengan tumbuhnya minat siswa dapat berpengaruh terhadap prestasi belajar.

Model VAK memiliki tahap-tahap yang menuntun pembelajaran menjadi tidak membosankan sehingga mampu menarik minat peserta didik untuk belajar IPA. Dengan menggunakan model pembelajaran VAK bahwa pada tahap persiapan peserta didik merasa nyaman dengan suasana kelas, peserta didik diberi appersepsi dan serta motivasi untuk belajar. Tujuannya adalah agar peserta didik semangat dalam mengikuti proses pembelajaran dan untuk mengetahui manfaat dari materi yang dipelajari.
Pada tahap penyampaian dan pelatihan yaitu peserta didik diminta untuk memberi tanggapan pada gambar yang ditampilkan di papan tulis. Saat guru menampilkan gambar dengan menggunakan proyektor peserta didik terlihat semangat dalam belajar tetapi peserta didik masih kurang berani atau malu-malu jika diminta guru untuk menyampaikan pendapat mengenai gambar tersebut. Kemudian peserta didik diminta untuk mendengarkan penjelaskan sedikit materi yang disampaikan oleh guru. Kemudian peserta didik diminta untuk bekerja dalam kelompok untuk melakukan percobaan tentang sifat-sifat cahaya. Guru menyiapkan alat dan bahan percobaan serta melakukan percobaan terlebih dahulu dan peserta didik diminta untuk memperhatikan langkah kerja yang dilakukan guru di depan kelas. Setelah guru selesai melakukan percobaan kemudian masing-masing perwakilan kelompok diminta untuk mengambil alat dan bahan percobaan dan LKPD yang telah disediakan guru di depan kelas. Akan tetapi peserta didik juga masih banyak yang kebingungan pada saat melakukan percobaan seperti sebagian peserta didik tidak tahu cara menyelesaikan percobaan melalui langkah-langkah yang ada di LKPD. Setelah peserta didik selesai melakukan percobaan masing-masing perwakilan kelompok diminta untuk mempresentasikan hasil diskusi dengan kelompok dan kelompok yang lain diminta untuk bertanya atau memberi tanggapan kepada kelompok yang tampil. Ketika membuat kesimpulan hasil diskusi hanya beberapa kelompok yang mampu menyimpulkannya dilihat dari hasil LKPD dan pada saat kelompok lain persentasi sedikit yang menanggapi hasil persentase karena peserta didik belum mengetahui cara menanggapi. Pada tahap akhir peserta didik diberi umpan balik mengenai materi yang 
dipelajari dan peserta didik juga diberi kesempatan untuk menyimpulkan materi yang telah dipelajari hari ini.

Adanya perbedaan nilai rata-rata posttest di kelas eksperimen dan nilai rata-rata posttest di kelas kontrol yang signifikan menunjukkan bahwa penerapan model pembelajaran VAKberpengaruh terhadap hasil belajar IPA siswa. Besarnya pengaruh antara Pembelajaran dengan Model VAK dan Model Pembelajaran Konvensional dapat dilihat dari analisis deskriptif. Analisis deskriptif menunjukkan bahwa skor hasil belajar kelompok eksperimen lebih baik dari pada kelompok kontrol. Dengan demikian, dapat disimpulkan bahwa model VAK lebih baik secara signifikan dari pada pembelajaran konvensional dalam meningkatkan hasil belajar. Adapun faktor yang mendukung pembelajaran IPA dengan menggunakan model VAK adalah guru yang mempunyai kreatifitas yang optimal dalam pembelajaran (Alditia, Ade Yayang Tri, 2016).

\section{SIMPULAN}

Berdasarkan hasil analisis dan pembahasan yang telah dilaksanakan dapat disimpulkan bahwa terdapat perbedaan hasil belajar IPA peserta didik kelas IV SD Negeri 147 Pekanbaru yang signifikan antara kelas eksperimen dan kelas kontrol dengan penerapan model pembelajaran VAK. Selain itu model VAK ini juga dapat meningkatkan aktivitas guru dan peserta didik dalam proses pembelajaran sehingga model ini efektif dan efisien untuk digunakan.

Berdasarkan hasil penelitian, pembahasan serta simpulan yang telah dijelaskan, maka peneliti menyampaikan rekomendasi sebagai berikut:
1. Untuk meningkatkan hasil belajar IPA peserta didik disekolah, diharapkan kepada guru untuk menambah variasi model mengajar dan menjadikan model VAK ini menjadi salah satu model alternatif.

2. Bagi peneliti selanjutnya yang ingin meneliti mengenai model pembelajaran VAKuntuk meningkatkan hasil belajar IPA peserta didik hendaknya betul-betul menguasai dan mempersiapkan dengan matang karena model pembelajaran VAKini membutuhkan perlengkapan khusus.

\section{DAFTAR PUSTAKA}

Alditia, Ade Yayang Tri,. Gusrayani, Diah \& Panjaitan, R.L. (2016). Pengaruh Model Visual, Auditory, dan Kinestethic (VAK) terhadap Hasil Belajar Siswa Pada Materi Sifat-sifat Cahaya. Jurnal Pena Ilmiah. 1(1): 351-360.

Hartanti, Kartika. (2014) Pengaruh Model Pembelajaran VAK (Visualisasi, Auditori, Kinestetik) terhadap Prestasi Belajar PAI Pada Sisiwa di SDN Tlogomulyo Temanggung. UIN Sunan Kalijaga.

Hermita, N. 2008. Pembelajaran IPA Dengan Model Inkuiri Terbimbing Untuk Meningkatkan Pemahaman Konsep Dan Keterampilan Proses Sains Siswa Sekolah Dasar. Tesis. JurusanPendidikan IPA SD FKIP UPI. TidakDiterbitkan.

Shoimin, A. 2014. 68 Model Pembelajaran Inovatif dalam kurikulum 2013. AR-Ruzz Media. Yogyakarta. http://download.portalgaruda.org. (diakses 20 Desember 2017).

Sundayana, R. 2014. Statistik Penelitian Pendidikan. Alfabeta. Bandung. 
Sugiyono. 2012. Metode Penelitian

Pendidikan (Pendekatan Kuantitatif,

Kualitatif, dan $R \& D)$. Alfabeta.

Bandung.

Suryadin, Wayan. M., Kusmiyati. 2017.

Pengaruh Model Pembelajaran

Visual Auditorial Kinestetik (VAK)

terhadap Motivasi dan Hasil Belajar

IPA Biologi Siswa Kelas VIII SMP

Negeri 3 Gunungsari Tahun Ajaran

2015/2016. J. Pijar MIPA XII (1),

Maret 2017. 19-24. (Online).

http://jurnalfkip.unram.ac.id.

(diakses 8 Januari 2018).

Trianto. 2015. Mendesain model pembelajaran inovatif, progresif, dan kontektual. Jakarta:

Prenadamedia Grup. 